\title{
Telejornalismo e mito: da vitória antecipada ao fracasso dos "heróis" brasileiros na Copa do Mundo pela narrativa do Jornal Nacional
}

\author{
Telejournalism and myth: from the anticipated victory to the failure of the \\ brazilians "heroes" in the World Cup for the narrative of the Jornal Nacional
}

\section{Teleperiodismo y mito: de la victoria anticipada al fracaso de los "héroes" brasileños en la Copa del Mundo por la narrativa de Jornal Nacional}

Flávio Porcello

Greetchen Ferreira Ihitz ${ }^{2}$

\begin{abstract}
Resumo
Este artigo tem como tema a Copa do Mundo de Futebol na televisão aberta brasileira. O presente trabalho é um recorte da pesquisa de mestrado desenvolvida na área de Jornalismo e Processos Editoriais e tem como objetivo apresentar parte dos resultados alcançados durante dois anos de estudos. Para isso, são analisadas duas reportagens veiculadas no Jornal Nacional da Rede Globo, a primeira integra a Série Seleção, exibida antes do megaevento esportivo, e a segunda constitui o corpus das matérias veiculadas sobre a equipe brasileira durante o Mundial de Futebol. Ambas apresentam Thiago Silva, capitão da Seleção, como o personagem principal. O material foi investigado a partir da Análise de Conteúdo sistematizada por Bardin (2011). Com base nas reportagens analisadas, fica evidente que o Jornal Nacional produz um discurso que constrói o herói antes da Copa do Mundo, a fim de vender o produto no qual está calcada uma grande cobertura midiática. Porém, quando o desempenho não é o mesmo que foi prometido nas histórias das façanhas heroicas dos atletas, a desconstrução dos personagens ganha força pelo uso do estereótipo negativo. Na fundamentação teórica deste estudo, foram utilizados, entre outros, os conceitos de Campbell (2005), Eliade (1989), Jung (1977), Durand (1997), Ferrés (1998), DaMatta (2006), Wolton $(2011,2006)$, Motta $(2002,2013)$ e Coutinho (2012).
\end{abstract}

Palavras-Chave: Telejornalismo. Jornal Nacional. Mito. Herói. Copa do Mundo.

\begin{abstract}
This article has as its theme the Football World Cup in the Brazilian broadcast television. The present work is a cut of the masters research developed in the area of Journalism and Editorial Processes and aims to present part of the results achieved during two years of studies. For that, two reports are analyzed in the Jornal Nacional on the Rede Globo Network, the first part of the Selection Series, which was shown before the mega-sport event, and the second is the corpus of the reports about the Brazilian team during the World Cup. Both feature Thiago Silva, selection captain, as main character.The investigation occurred with content analysis by Bardin (2011). Based on the reports analyzed it is clear that the Jornal Nacional produces a discourse that constructs the hero before the World Cup to sell the product in which it is modeled a large media coverage. However, when the

\footnotetext{
${ }^{1}$ Jornalista diplomado, bacharel em Ciências Jurídicas e Sociais pela Universidade Federal do Rio Grande do Sul, Mestre e Doutor em Comunicação Social pela PUCRS. Professor do Programa de Pós-graduação em Comunicação e Informação UFRGS. Vice-coordenador do Grupo de Pesquisa GPTV. E-mail: flavio.porcello@ufrgs.br.

2 Jornalista, Relações Públicas e Mestre em Comunicação e Informação pela Universidade Federal do Rio Grande do Sul. Integrante do Grupo de pesquisa GPTV.E-mail: fgreetchen@ hotmail.com.
}

Comun. \& Inf., Goiânia, GO, v. 21, n. 1, p. 89-108, jan./mai. 2018 
promised performance is not the same, increases the deconstruction of the athletes using negative stereotypes. In the theoretical framework of this study were used, among others authors, the concepts of Campbell ( 2005), Eliade (1989), Jung (1977), Durand (1997), Ferrés (1998), DaMatta (2006), Wolton (2006, 2011), Motta (2002, 2013) e Coutinho (2012).

Keywords: Telejournalism. Jornal Nacional. Myth. Hero. World Cup.

\section{Resumen}

Este artículo tiene como tema la Copa del Mundo de Fútbol en la televisión abierta brasileña. El presente trabajo es un recorte de la investigación de maestría desarrollada en el área de Periodismo y Procesos Editoriales y tiene como objetivo presentar parte de los resultados alcanzados durante dos años de estudios. Para ello, se analizan dos reportajes publicados en el Jornal Nacional de Rede Globo de Televisión, el primero integra la Serie Selección, exhibida antes del megaevento deportivo, y el segundo constituye el corpus de las materias vehiculadas sobre el equipo brasileño durante el Mundial de Fútbol. Los dos presentan a Thiago Silva, capitán de la selección, como el personaje principal.El material fué investigado por la Análisis de Contenido sistematizada por Bardin (2011). Com base em los reportages analisados, queda evidente que Jornal Nacional produce un discurso que construye el héroe antes de la Copa del Mundo con el fin de vender el producto en el cual esta calcada una gran cobertura mediática. Pero, cuando el desempeño no es el mismo que fué prometido en las historias heroicas de los jugadores, la desconstrucción de los personages gana fuerza por el uso del estereotipo negativo. En la fundamentación teórica, deste estudio fueron utilizados los conceptos de Campbell (2005), Eliade (1989), Jung (1977), Durand (1997), Ferrés (1998), DaMatta (2006), Wolton (2006, 2011), Motta (2002, 2013) e Coutinho (2012).

Palabras clave: Teleperiodismo. Jornal Nacional. Mito. Héroe. Copa del Mundo.

\section{INTRODUÇÃO}

$$
\begin{aligned}
& \text { televisão tem mais de } 65 \text { anos de existência no Brasil e segue hegemônica, } \\
& \text { contrariando as previsões mais pessimistas que chegavam a apontar até } \\
& \text { mesmo o seu fim com o surgimento da internet. Nesse panorama que }
\end{aligned}
$$

evolui a cada dia, com a grande expansão das mídias sociais e dos dispositivos móveis, a TV aberta passa por uma transformação na busca pelos índices de audiência que têm se mostrado menores, mas o fato é que ela ainda se mantém como o principal meio de informação para boa parte dos brasileiros.

De acordo com a Pesquisa Brasileira de Mídia $2015^{3}$, a televisão continua como meio de comunicação predominante no país. Dos entrevistados, 95\% afirmaram ver televisão, 72\% possuem acesso à TV aberta e 79\% disseram que assistem TV para se informar. Em média,

\footnotetext{
${ }^{3}$ A Pesquisa Brasileira de Mídia 2015 foi encomendada pela Secretaria de Comunicação Social da Presidência da República e realizada pelo Ibope em 2014. Foram entrevistadas 18.312 pessoas maiores de 16 anos em 848 municípios. Disponível em: <http://www.secom.gov.br/atuacao/pesquisa/lista-de-pesquisas-quantitativas-equalitativas-de-contratos-atuais/pesquisa-brasileira-de-midia-pbm-2015.pdf>. Acesso em: 22 fev. 2015. Outro levantamento que mostra a dimensão da TV no país é a Pesquisa Nacional por Amostra de Domicílios (Pnad), realizada pelo IBGE, que aponta que 63,3 milhões de domicílios no Brasil possuíam TVs em 2013, o que corresponde a 97,2\% do total. Disponível em: <http://biblioteca.ibge.gov.br/visualizacao/livros/liv93373.pdf〉. Acesso em: 30 abr. 2015.
}

Comun. \& Inf., Goiânia, GO, v. 21, n. 1, p. 89-108, jan./mai. 2018 
os brasileiros passam 4h e 31 minutos na frente da televisão, de segunda a sexta-feira, e $4 \mathrm{~h}$ e 14 minutos, nos finais de semana. A faixa de maior audiência é das $20 \mathrm{~h}$ às $20 \mathrm{~h} 59$, na qual se encontra o Jornal Nacional da Rede Globo, o telejornal mais antigo no ar e o mais assistido no país, que é nosso objeto de estudo.

É nesse contexto que, em 2014, a emissora transmitiu a Copa do Mundo de Futebol, a segunda a ser realizada no Brasil ${ }^{4}$. Detentora dos direitos de transmissão do Mundial na TV aberta no país, a Globo exibiu séries especiais, mesmo antes do início do torneio, que foram levadas ao ar nos telejornais. A cobertura começa a ser intensificada na emissora com o objetivo de promover o produto Copa do Mundo. De acordo com levantamento do Ibope Repucom-Sponsorlink, o Brasil é um país que respira esportes e o futebol continua sendo o maior deles.

Dos entrevistados, $65 \%$ se declararam muito interessados ou interessados em futebol. Os que se disseram muito interessados $(42 \%)$ são considerados super fãs. Na pesquisa, quase metade dos super fãs disseram que frequentam estádios e levam as famílias aos jogos. Também consomem produtos de marcas oficiais ligadas ao esporte e praticam o futebol como atividade esportiva. O meio de comunicação que pode ser considerado protagonista no cotidiano dos torcedores que consomem futebol é a televisão. Segundo o levantamento ${ }^{5}, 77 \%$ acompanham o futebol de campo pela TV. Fora do horário das competições, a televisão também é o principal meio para buscar informações sobre os esportes favoritos para $94 \%$ dos entrevistados. Em anos de Copa, a paixão dos brasileiros pelo futebol fica mais evidente. Em 2014, o tempo médio diário em frente à TV aberta $^{6}$ foi de 5 horas, 52 minutos e 39 segundos. 33 minutos a mais se comparado com a Copa de 2010.

\footnotetext{
2 A primeira Copa do Mundo no Brasil foi realizada em 1950. Na ocasião, o Brasil disputou a final com o Uruguai e perdeu por 2 a 1, de virada, no Estádio do Maracanã, no Rio de Janeiro. A derrota ficou conhecida na história do futebol mundial como "Maracanaço".

${ }^{5}$ A pesquisa Ibope Repucom-Sponsorlink Brasil foi realizada em junho de 2014 e representa a população de internautas brasileiros. A amostra é de 1.000 entrevistados com mais de 18 anos nas cinco regiões geográficas Norte, Nordeste, Centro-Oeste, Sudeste e Sul. Disponível em: <http://www.ibopemedia.com/um-pais-querespira-esportes/>. Acesso em: 10 jul. 2015.

${ }^{4}$ A Pesquisa Retroperspectiva Investimento Publicitário 2014 Ibope Media-Monitor Evolution - dez. 2014. Cobertura de 42 mercados de TV aberta. Disponível em: $<$ http://www4.ibope.com.br/media/investimento_publicitario_2014/\#_ga=1.155130043.209644203.1436460462 $>$. Acesso em: 10 jul. 2015.
} 
Ao encontro desses índices, os grandes patrocinadores se fazem presentes na Copa do Mundo. A TV aberta foi o meio que mais se beneficiou com o Mundial de Futebol. Em junho de 2014 , houve um acréscimo de $42 \%$ no volume investido em comparação com o mesmo período de 2013. Os valores giraram em torno de mais de 7 milhões de reais. Os gêneros que mais se destacaram em investimentos publicitários em 2014 foram os esportes com crescimento de $42 \%$ e o futebol com aumento de $86 \%$.

Diante desses números, não é difícil entender os motivos pelos quais a Copa do Mundo ganha tanta visibilidade na televisão. No dia da estreia do Mundial, em 12 de junho, a Globo destinou mais de 12 horas da sua programação ao evento. Só o Jornal Nacional ${ }^{7}$ dedicou mais de $90 \%$ do seu espaço para assuntos relacionados à Copa. A cobertura seguiu esse padrão durante todo o mês de junho e uma parte de julho, quando outros assuntos voltaram ao dia a dia, tendo em vista o desempenho considerado insatisfatório da Seleção Brasileira e a redução do número de seleções participantes, à medida que a competição foi chegando à etapa final.

Com base nos dados citados acima, podemos dizer que o esporte ganha cada vez mais importância no Brasil e se fortalece pela mediação da TV. A cada megaevento esportivo acontece uma disputa pelos direitos de transmissão entre as emissoras. Em 2016, as Olimpíadas do Rio de Janeiro, as primeiras a serem realizadas na América do Sul, tiveram os direitos divididos por três emissoras na TV aberta: Rede Globo, Rede Bandeirantes e Rede Record. Como podemos ver, faz-se necessário discutir com mais intensidade essa relação crescente permeada de interesses dúbios e avaliar o papel social do jornalismo nesse processo.

O objetivo deste artigo é apresentar um recorte dos resultados alcançados na pesquisa desenvolvida durante o mestrado, que teve como proposta investigar como o Jornal Nacional constrói o mito do herói nas narrativas sobre os jogadores da Seleção Brasileira de Futebol antes da Copa do Mundo de 2014 e, a partir do momento que os jogadores e os resultados não inspiram confiança, verificar qual é a estratégia utilizada pelo telejornal para não se comprometer em relação à audiência. Para fins de análise deste trabalho, utilizamos duas reportagens que apresentam Thiago Silva, o capitão da Seleção Brasileira, como personagem

${ }_{5}^{5}$ Disponível em: <http://www.meioemensagem.com.br/home/midia/noticias/2014/06/16/Globodedicou-90-porcento-da-grade-a-Copa.html>. Acesso em: 30 jun. 2014. 
principal. A primeira integra a Série Seleção, exibida antes do megaevento esportivo, e a segunda faz parte do corpus das matérias veiculadas durante o Mundial de Futebol sobre a equipe brasileira. O material foi investigado a partir da Análise de Conteúdo sistematizada por Bardin (2011).

\section{MITO, HERÓI E FUTEBOL}

Estudar os mitos requer um mergulho em mundo mágico e instigante que nos leva a uma viagem pela psique, pelos sonhos, pelas civilizações arcaicas, suas tradições e crenças. Manifestações culturais que estão envoltas em um caráter sobrenatural da criação do Cosmos. A definição de mito não é uma tarefa fácil e para isso nos apoiamos em um dos principais estudiosos sobre o assunto. Mircea Eliade, historiador, filósofo e mitólogo que descreve o caráter múltiplo e complexo de interpretação do mito:

[...] o mito conta uma história sagrada, relata um acontecimento que teve lugar no tempo primordial, o tempo fabuloso dos "começos". Noutros termos, o mito conta como, graças aos feitos dos Seres Sobrenaturais, uma realidade passou a existir, quer seja a realidade total, o Cosmos, quer apenas um fragmento: uma ilha, uma espécie vegetal, um comportamento humano, uma instituição. É sempre, portanto, a narração de uma "criação": descrevese como uma coisa foi produzida, como começou a existir (ELIADE, 1989, p. 13).

O mito fala do real, segundo o mitólogo, de algo que ocorreu definitivamente e assim se manifestou, ou seja, uma história que pode ser considerada verdadeira. Os mitos para serem passados adiante requerem um ritual específico. Assim, eles estão associados a ritos, como cerimônias de iniciação, de passagem da infância para a adolescência, nascimento, casamentos e morte. Barthes (1980) confere ao mito o caráter de fala, de um sistema de comunicação. $\mathrm{O}$ autor acredita que tudo pode ser considerado um mito, já que ele não se define pelo objeto da sua mensagem e sim pela maneira com que essa mensagem é proferida, pela sua forma. A fala é considerada uma mensagem e não é necessariamente oral, sendo formada por escritas ou representações: "o discurso escrito, assim como a fotografia, o cinema, a reportagem, o esporte, os espetáculos, a publicidade, tudo isso pode servir de suporte à fala mítica" (BARTHES, 1980, p. 132). 
De acordo com Jung ${ }^{8}$ (1977, p. 90) "a origem dos mitos remonta ao primitivo contador de histórias, aos seus sonhos e às emoções que a sua imaginação provocava nos ouvintes". Para o psiquiatra, o inconsciente é dirigido por tendências instintivas, arcaico-mitológicas. Quando Jung (1977) fala de inconsciente temos que deixar claro ao que ele se refere. Os conteúdos do inconsciente pessoal são chamados de complexos afetivos e os conteúdos do inconsciente coletivo ${ }^{9}$ são denominados de arquétipos. Segundo Jung (1977), na experiência prática os arquétipos unem imagem e emoção, pois quando carregada de emoção a imagem ganha energia psíquica e pode trazer as mais variadas consequências.

Os mitos se organizam com coerência dentro das civilizações e a essa organização damos o nome de imaginário. Para o antropólogo francês Gilbert Durand (1997), todo o pensamento humano se dá na forma de representação e se configura por meio das articulações simbólicas. Dessa forma, influencia a constituição dos indivíduos, culturas e sociedades ao contemplar as relações antropológicas e as manifestações arquetípicas. Segundo ele, o mito é:

Um sistema dinâmico de símbolos, arquétipos e esquemas, sistema dinâmico que, sob o impulso de um esquema, tende a compor-se em narrativa. $\mathrm{O}$ mito é um esboço de racionalização, dado que utiliza o fio do discurso, no qual os símbolos se resolvem em palavras e os arquétipos em ideias (DURAND, 1997, p. 63).

No imaginário, um dos arquétipos mais conhecidos, e que se mantém vivo há séculos, é a figura do herói. Campbell (2005), norte-americano que dedicou a vida ao estudo e interpretação do mito, estabeleceu que a aventura do herói tem um caminho comum representado nos rituais de passagem: separação-iniciação-retorno, a qual o mitólogo chama de unidade nuclear do monomito. A partida ou separação é o momento no qual o herói é convocado pelo destino, recebe o chamado à aventura. A iniciação é composta por diversas aventuras do herói ao longo do percurso, um caminho perigoso, de provas, tentações e conquistas. O retorno é o momento no qual o aventureiro volta para casa e carrega os ensinamentos, a sabedoria e os poderes adquiridos ao longo da jornada.

O herói possui uma infinidade de faces para Campbell (2005), dependendo do olhar que se lance em cada cultura. Ele pode ser protagonista da religião, como Buda, dos contos de fadas, do folclore, das mitologias e acaba representando as várias fases de uma mesma

\footnotetext{
${ }^{8}$ Carl Gustav Jung foi o fundador da psicologia analítica. O psiquiatra e psicoterapeuta suíço desenvolveu os conceitos de personalidade extrovertida e introvertida, arquétipos e inconsciente coletivo.

${ }^{9}$ Para Jung, o inconsciente coletivo é a parte da psique que tem características instintivas, é inato e herdado. Seus conteúdos e modos de comportamento são os mesmos em todos os lugares e em todos os homens (JUNG, 1977, p.10).
}

Comun. \& Inf., Goiânia, GO, v. 21, n. 1, p. 89-108, jan./mai. 2018 
história. Ao longo da jornada, o herói demonstra as virtudes das quais é dotado e passa por uma série de obstáculos. Essas características ${ }^{10} \mathrm{o}$ acompanham em sua perigosa caminhada e justificam os motivos pelos quais recebeu o chamado à aventura:

Amor - os poderes divinos sempre estiveram presentes no coração do herói. Ele é dotado de talento para obter a benção do amor, que é a própria vida. Dessa maneira, ele simboliza uma imagem redentora e criadora que se encontra escondida em cada ser humano;

Coragem - a fim de realizar a tarefa para a qual foi chamado, o herói precisa deixar os medos de lado e enfrentar o percurso desconhecido e sombrio da iniciação. É uma radical transferência do mundo externo para o mundo interno da psique;

Persistência - ao vencer as limitações locais e pessoais e se manter determinado na jornada, embora possa fraquejar em algum momento, o herói persiste no seu objetivo pré-determinado. Podemos dizer que é a luta contra todos os medos internos do ser humano que precisam ser dominados;

Proteção - O primeiro encontro da jornada do herói se dá com uma figura protetora, a qual pode ser um ancião, uma anciã, uma fada-madrinha ou uma virgem, no caso das lendas dos santos cristãos. Essas figuras oferecem ao aventureiro amuletos de proteção contra as forças obscuras que ele vai enfrentar. São a representação do poder benigno e protetor do destino; Fé - Em um mundo desconhecido e cheio de perigos, o herói se apega aos deuses, às divindades protetoras do universo e crenças mais profundas para seguir em sua caminhada. Quando encontra seu Deus, o herói encontra a si mesmo, ambos são entendidos como a parte externa e interna de um único mistério auto-refletido;

Desprezo - Apesar de ser dotado de dons excepcionais e geralmente respeitado pela sociedade da qual faz parte, o herói pode não receber o reconhecimento merecido ou ser objeto de desdém. Ele ou o mundo no qual está inserido sofrem de uma deficiência simbólica. Cabe ao herói reafirmar a sua condição e trazer de volta a confiança, que pode se traduzir como uma autoafirmação da personalidade;

Derrota - No sombrio caminho interior ao qual se propôs trilhar, o herói pode perder, em algum momento, no campo de batalha. Local que simboliza o campo da vida no qual o sentimento de culpa pode deixar o coração amargurado, seguido de uma recusa em prosseguir.

\footnotetext{
${ }^{10}$ Ao longo da obra O Herói de Mil Faces, Campbell (2005) apresenta as características do herói que aparecem em diversas mitologias, fábulas e religiões da humanidade. A classificação acima é fruto das inferências dos autores desta pesquisa a partir do que é descrito na obra.
}

Comun. \& Inf., Goiânia, GO, v. 21, n. 1, p. 89-108, jan./mai. 2018 
Os que persistem no caminho demonstram o amadurecimento psicológico. Nesses momentos, assim como no início da jornada, o herói pode contar com a ajuda de forças sobrenaturais;

Vitória - Após executar as provas e alcançar o objetivo proposto, o herói faz a passagem pelo limiar do retorno, que o leva do reino místico à terra cotidiana. Ele pode chegar até esse caminho por meio das suas forças internas, resgatado com ajuda externa ou conduzido por divindades orientadoras;

Sabedoria - O herói volta para sua terra ou comunidade com a benção obtida que restaura o mundo, também chamada de elixir. Traz ensinamentos na sua reintegração à sociedade;

Renascimento - Ao voltar, o herói reemerge do reino do terror no qual enfrentou diversas provações e, por vezes, até a morte. O significado é o renascer para uma nova vida, após ter enfrentado seus fantasmas internos. É a passagem da infância para a maturidade.

O mito do herói está presente nos sonhos dos indivíduos, as suas histórias variam em termos de detalhes entre as civilizações, mas guardam uma fórmula universal. As façanhas do herói atravessam gerações e a sua jornada tem uma grande importância para a psicologia profunda em termos de afirmação da personalidade individual e para a sociedade, ao promover uma identidade coletiva (HENDERSON, 1977).

É na sociedade midiatizada que se constitui um espaço privilegiado de produção de discurso, na qual estão os heróis contemporâneos dos espetáculos esportivos de diversas modalidades. Espetáculos que não teriam sentido sem as figuras mitológicas. "Sem essas figuras ele perderia a força e sabemos que assistimos a ele tanto pelo prazer do jogo coletivo quanto por aquele gerado pelos desempenhos individuais" (LOVISOLO, 2000, p. 16). O esporte é o lugar no qual a relação mítico-religiosa continua a se dar, se o considerarmos como um rito. Tanto em relação ao próprio evento, ao jogo de futebol com suas regras de início, meio e fim, aos jogadores e seus ritos e também em relação ao torcedor e sua paixão.

Segundo DaMatta (2006, p. 163), o futebol "é uma importante agência de dramatização da sociedade brasileira". Afinal, é a atividade que de alguma maneira une uma sociedade desigual na hora de torcer e proporciona ao povo uma experiência de vitória e êxito ao sofrer e vibrar pelo seu clube e heróis. Nessa mesma perspectiva, o futebol torna latente o sentimento de igualdade e justiça social. E é por unir o formal com o informal e as leis com a realidade que no Brasil "o futebol se transformou num campo imbatível de todo o tipo de emoções" (DAMATTA, 2006, p.165).

O futebol é um terreno extremamente fértil para a produção de ritos e mitos na sociedade contemporânea, principalmente os relacionados ao herói. "Dotados de talento e

Comun. \& Inf., Goiânia, GO, v. 21, n. 1, p. 89-108, jan./mai. 2018 
carisma, o que os singulariza e diferencia dos demais, estes "heróis" são paradigmas dos anseios sociais e, através das narrativas de suas trajetórias de vida, uma cultura se expressa e se revela" (HELAL, 1999, p. 39).

Essas narrativas construídas pela mídia encontram maior significado ao considerarmos o futebol como um fenômeno de comunicação que produz imagens e mensagens, constituindo-se em um lugar onde o público se identifica e se une em torno de um grande espetáculo. Todo esse processo tem seus caminhos atrelados à psique, ao imaginário e também à maneira pela qual as notícias são construídas pelos jornalistas, principalmente, na televisão. Notícias narradas com histórias que têm muito da dramaturgia e acabam por reproduzir o mito na sociedade.

\section{NOTÍCIA NA TV E DRAMATURGIA}

Apesar da objetividade e da busca pela veracidade, o jornalista não se afasta do mundo mítico. De acordo com Motta (2002), as notícias podem ser vistas como uma forma de transmissão cultural e que primam pela repetição. "A recorrência regular de conteúdos diversos (crimes, denúncias, corrupção, julgamentos, punições, vitórias, derrotas, recompensas) reforça as percepções de padrões culturais, modelos éticos e arquétipos no inconsciente coletivo" (MOTTA, 2002, p. 67). Na mesma linha, Bird e Dardenne (1999) acreditam que as notícias podem ser vistas como um mito, pois colocam ordem na desordem, falam do bem e do mal, trazem explicações para temas complexos por meio das narrativas ritualísticas. Na contemporaneidade, ao ler, assistir ou ouvir uma notícia, os indivíduos acabam por repetir um ritual diário.

O mito só tem significado no contar; os temas e os valores culturais só existem se forem comunicados. Obviamente não existe um único mito ou narrativa que seja meramente repetido; no entanto, para continuar a ter força, os mitos devem ser constantemente recontados. Mais, os temas são rearticulados e reinterpretados ao longo do tempo, temas que provêm da cultura e para a qual retornam (BIRD; DARDENNE, 1999, p. 267).

No caso da televisão, pode-se dizer que o meio agrada porque conta histórias, é o reino do relato e da fabulação, segundo Ferrés (1998). Os relatos exercem um fascínio porque incidem no emocional e promovem uma oportunidade do indivíduo encontrar a si mesmo e dar sentido às pulsões internas e externas. Por isso, o autor acredita que o espetáculo televisivo é uma experiência mítica. O espectador verte os desejos sobre as imagens originando um sentido para elas e, ao mesmo tempo, recebe um sentido advindo delas:

Comun. \& Inf., Goiânia, GO, v. 21, n. 1, p. 89-108, jan./mai. 2018 
Efetivamente, o mito é uma história que tem a força do símbolo básico, do símbolo que tem conexão com a experiência humana mais profunda. $\mathrm{O}$ mito tem ao mesmo tempo a atração do relato e a atração do significado profundo, embora muitas vezes este não seja percebido de maneira consciente (FERRÉS, 1998, p. 94).

Wolton (2011, p. 71) acredita que os profissionais das redações têm um papel fundamental na sociedade, pois "não há informação-notícia sem jornalistas para produzi-las e, principalmente, para dar-lhes legitimidade". A televisão, para o sociólogo, continua sendo um instrumento de promoção cultural e igualdade de acesso, o que seria uma das causas principais do seu sucesso. Para Wolton (2006), o mais importante acaba sendo não o que vemos na TV, mas a conversa que tem origem em torno daquilo que vimos. Dessa maneira, a televisão se transforma em um objeto de conversação que se dá, num primeiro momento, em casa e depois fora dela. Por estar em um espaço nacional de comunicação, a televisão constitui o laço social de uma comunidade nacional.

Como seres narrativos, também somos atores, personagens e ouvintes das próprias narrativas. Segundo Motta (2013), estudar as narrativas é compreender o sentido da vida e refletir sobre o significado da experiência humana e sobre o que as narrativas realizam enquanto atos de fala. Conforme o autor, as narrativas representam a realidade, mas também apresentam e organizam o mundo ajudando os homens a constituir a realidade.

Motta (2013, p. 174) destaca em seus estudos que a personagem é a figura central da narrativa, "é o eixo do conflito em torno do qual gira toda a intriga". Lembra, também, para efeitos de análise, que mesmo nas narrativas fáticas do jornalismo o referencial não é composto de pessoas reais, mas de personagens fabricados pelo discurso; o que o autor denomina "figuras de papel". A partir da maneira que as pistas e os estímulos do texto são apresentados, a imagem da pessoa física se dissipa no ato da leitura e se confunde com figuras-tipo como o herói, o vilão, o príncipe, o sapo e a princesa.

Quando Luiz Gonzaga Motta (2013) se refere ao personagem como figura central da narrativa, o autor afirma que a identificação ou a rejeição da audiência vai se dar em relação aos estereótipos construídos e divulgados pela mídia. Personagens do mundo da política, do espetáculo e dos esportes são retratados pelo jornalismo diariamente e suscitam simpatia, paixão, dor, raiva, angústia e outros sentimentos, assim como ocorre na arte e na literatura. No telejornalismo os personagens acabam se tornando o eixo das histórias e, frequentemente, por 
meio do uso de estereótipos, são identificados pelos telespectadores como mocinhos e bandidos, heróis ou vilões.

Para Ferrés (1998), os estereótipos ${ }^{11}$ são uma manifestação clara da ideologia latente em um discurso e são a inversão da sedução. Podem ser considerados, ao mesmo tempo, verdadeiros e falsos. Verdadeiros porque se baseiam em aspectos extraídos da realidade e falsos porque a generalização pode ser vista como uma traição a uma realidade que é complexa e contraditória. Os estereótipos ainda podem ser considerados a vitória do inconsciente sobre o consciente, possibilitando o envolvimento emocional do receptor. De acordo com Ferrés (1998), o estereótipo reflete a ideologia dominante e tende a perpetuar e petrificar as coisas, isolando e desinformando:

[...] a televisão cumpre a sua função de agente socializador através de um processo lento, mas perseverante de apresentação de concepções estereotipadas da realidade que se vão sedimentando de forma inconsciente. A exposição constante a imagens estereotipadas da realidade leva à construção de algumas representações mentais da realidade igualmente estereotipadas (FERRÉS, 1998, p. 140).

Coutinho (2012) defende que as notícias no telejornalismo se estruturam como um drama cotidiano e, assim como Motta (2013), acredita que elas se organizam em torno de conflitos nos quais estão presentes personagens e estereótipos. A autora propõe que a edição das notícias e do telejornalismo no Brasil tem uma estrutura narrativa característica do drama, esclarece que nelas é peculiar a conclusão de uma ação que se daria por meio da apresentação de uma lição de moral, de uma mensagem educativa, na maioria das vezes, acrescida de juízo de valor.

Isso se daria por meio do texto do jornalista ou da edição do material e, a partir desse momento, reafirmariam-se os papéis dos mocinhos e dos heróis, enquanto a punição dos personagens identificados como "maus" ou vilões seria justificada. Conforme Coutinho (2006), na televisão e no telejornalismo a compreensão da dramaturgia remete a uma organização narrativa. Porém, ela não pode ser apenas textual, visto que existem outros elementos em cena como a paginação do telejornal, a exacerbação dos recursos audiovisuais e o tom emocional dos textos.

11 Para Ferrés (1998, p. 135), os estereótipos são representações sociais, institucionalizadas, reiteradas e reducionistas. São representações sociais porque pressupõem uma visão compartilhada que um coletivo social possui sobre outro coletivo social. São reiteradas porque são criadas com base na repetição e são reducionistas porque transformam uma realidade complexa em algo simples.

Comun. \& Inf., Goiânia, GO, v. 21, n. 1, p. 89-108, jan./mai. 2018 


\section{METODOLOGIA E PROCEDIMENTOS DE ANÁLISE}

A metodologia adotada neste estudo é a Análise de Conteúdo, sistematizada por Bardin (2011), que se estrutura em três polos cronológicos: a pré-análise, que é a fase da organização da pesquisa; a exploração do material, referente à administração sistemática das decisões tomadas; e o tratamento dos resultados, que é a validação dos dados que foram obtidos.

Para a análise, neste artigo, após a leitura flutuante, definimos uma reportagem da Série Seleção (veiculada em 26/05/2014) e uma reportagem exibida durante a Copa do Mundo (veiculada em 03/07/2014). Ambas têm como personagem o capitão Thiago Silva. A escolha se justifica em função do zagueiro ser um dos personagens que mais apareceu durante a realização do Mundial de Futebol, com o intuito de comparar, quando possível, como esse jogador foi mostrado antes do início e no transcorrer da Copa do Mundo.

É importante frisar que a reportagem, durante a Copa do Mundo, foi escolhida, também, por apresentar de forma mais evidente as estratégias utilizadas pelo JN em relação aos jogadores quando os resultados em campo não eram os esperados. A primeira matéria a ser descrita, na Tabela 1, compõe a Série Seleção.

$\mathrm{Na}$ pesquisa, as unidades de registro foram definidas como palavra, frase e personagem e a unidade de contexto, a reportagem. Com referencial teórico em Campbell (2005), foram criadas seis categorias temáticas para as características do mito do herói (vitória, amor, derrota, renascimento, persistência e desprezo). Da mesma forma que nas categorias citadas anteriormente, foi definido pelo método quantitativo o primeiríssimo plano (PPP) para compor os quadros de análise, pois acreditamos que a produção de sentido na televisão se dá por meio do imbricamento da narrativa verbal e da narrativa audiovisual.

Incialmente, foram elaboradas tabelas em formato de script nas quais as reportagens foram transcritas e estabelecemos a narrativa audiovisual (decupamos as imagens e a sonorização) e a narrativa verbal, que é o texto da reportagem. Nesse texto, já destacamos em negrito as palavras ou frases que remetem às características do herói (CAMPBELL, 2005). Na sequência, elaboramos outra tabela, conforme mostrada abaixo, na qual estabelecemos as características do herói, que estão presentes na reportagem com a narrativa audiovisual e verbal correspondentes, a fim de alcançar o objetivo proposto. 
Tabela 1 - Ficha das características do herói na reportagem exibida em 26.05.2014

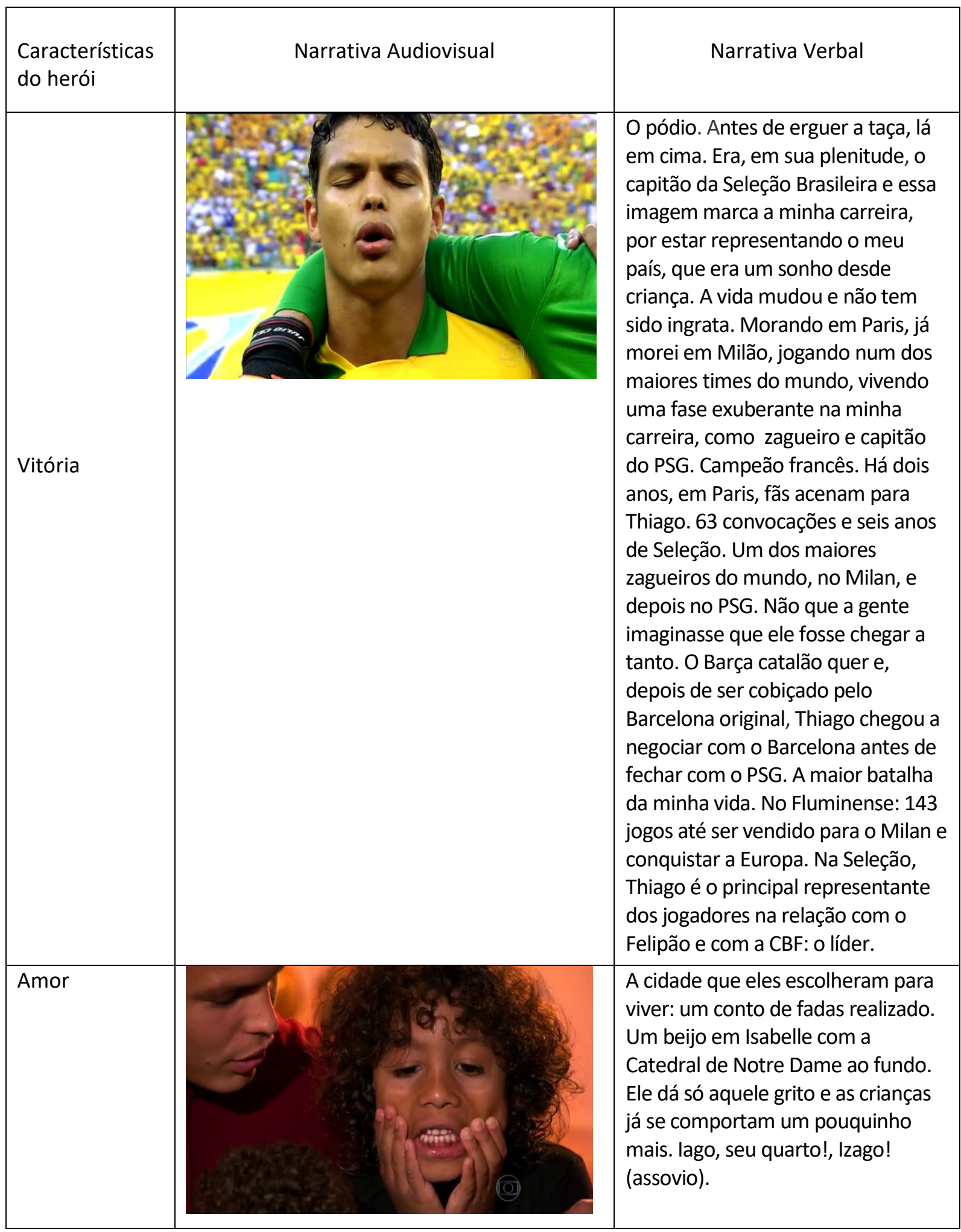




\begin{tabular}{|l|l|}
\hline Derrota & $\begin{array}{l}\text { Thiago nem estaria por aqui. Estava } \\
\text { decidida a fazer um aborto. Foi } \\
\text { reprovado nas tentativas de entrar } \\
\text { em um grande clube do Rio e por lá } \\
\text { parou mesmo. Com Tuberculose, } \\
\text { ficou seis meses internado na } \\
\text { Rússia. A pior parte da vida dele e } \\
\text { nossa. Engordei 10 quilos naquela } \\
\text { minha doença. O dia dele dentro } \\
\text { daquele quarto era deprimente. } \\
\text { Tinha aquele ponto de interrogação } \\
\text { se propriamente eu poderia voltar a } \\
\text { jogar futebol profissional ou só } \\
\text { amador ou, de repente, nem } \\
\text { amador. }\end{array}$ \\
\hline Renascimento & $\begin{array}{l}\text { Ele a convenceu a ter o bebê. Não } \\
\text { deixou que eu fizesse e o caçula } \\
\text { veio ao mundo. Voltou e justo } \\
\text { depois da doença a carreira } \\
\text { decolou. }\end{array}$ \\
\hline Persistência &
\end{tabular}

Fonte: Os autores, 2016

Identificadas as características relacionadas ao mito do herói, prosseguiu-se com a exploração do material em busca da segunda parte do objetivo. No corpus, Copa do Mundo, a análise foi fundamentada em Ferrés (1998), que propõe que os estereótipos são a inversão da sedução e, por sua característica reducionista, favorecem a simplificação da realidade atuando diretamente no inconsciente do telespectador.

Da mesma forma que se procedeu na reportagem da Série Seleção, foram elaboradas tabelas com a transcrição da matéria e nela estabelecidas a narrativa audiovisual e a narrativa verbal. Nesse texto, os pesquisadores destacaram em negrito as palavras ou frases que remetem ao estereótipo e que serão mostradas no quadro de análise que virá a seguir,

Comun. \& Inf., Goiânia, GO, v. 21, n. 1, p. 89-108, jan./mai. 2018 
conforme a Tabela 2. Cabe salientar, que a imagem que aparece no quadro é a que reforçou na edição da reportagem a condição de "desequilibrados emocionais".

Tabela 2 - Estereótipo na reportagem exibida em 03.07.2014

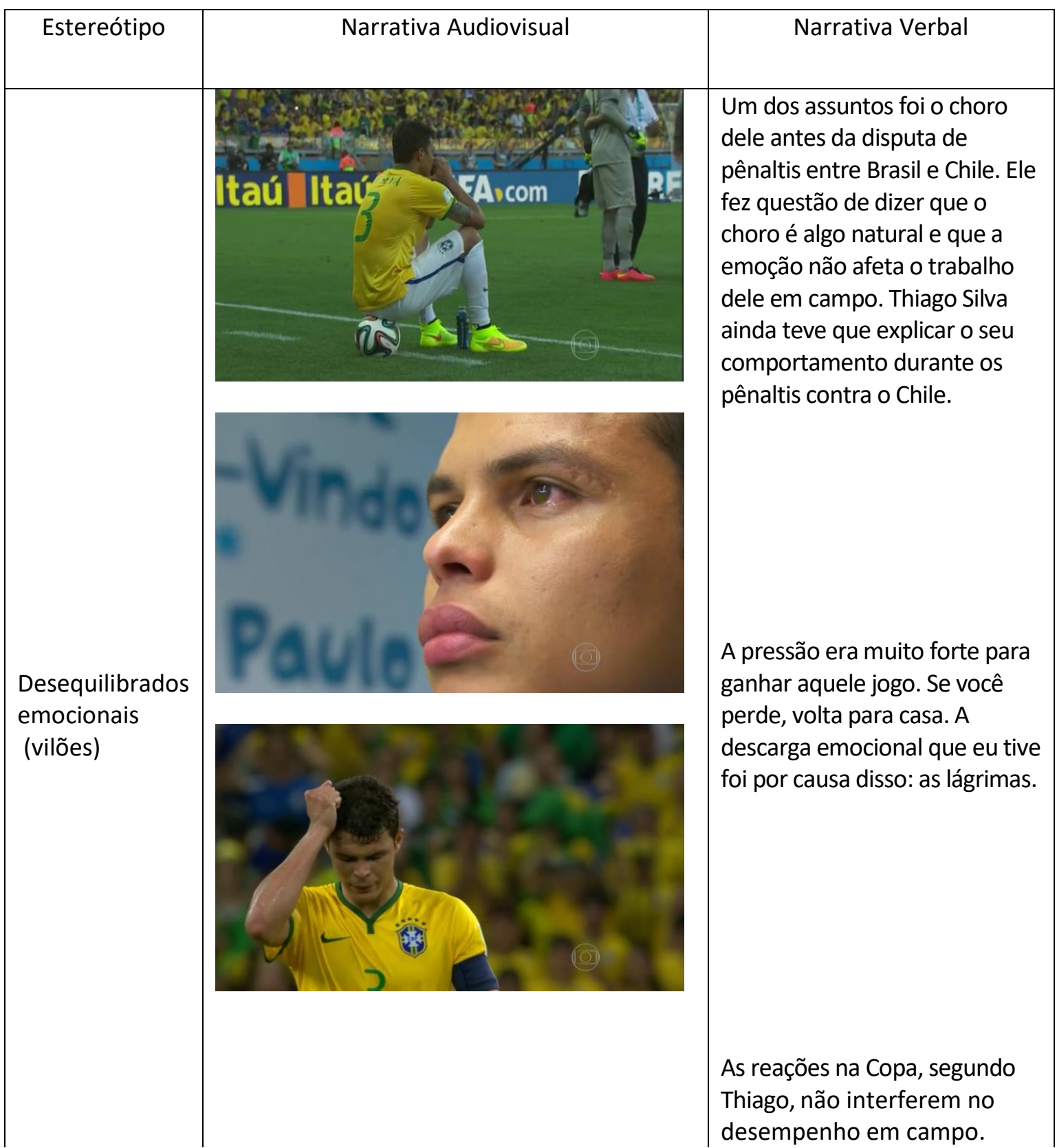




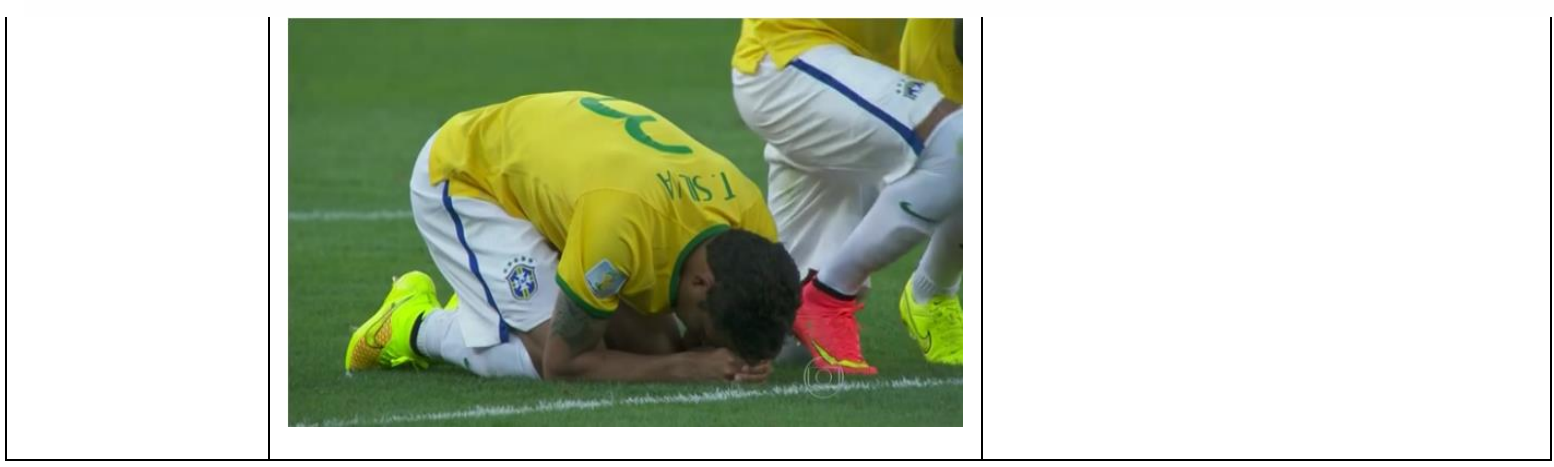

Fonte: Os autores, 2016

\section{CONSIDERAÇÕES FINAIS}

Ao investir cifras não reveladas, a Rede Globo, emissora líder em audiência no país, utiliza todos os recursos multiplataforma que possui para promover os eventos das quais é detentora. No caso da Copa do Mundo de Futebol, nosso objeto de estudo, uma das estratégias utilizadas é direcionar a cobertura jornalística para o evento. Obrigatoriamente, o Jornal Nacional e os demais telejornais da rede abrem espaço para a divulgação do torneio que é considerado o mais importante no mundo esportivo. Em 2014, o tema ganhou mais relevância pelo fato do Mundial ser disputado pela segunda vez no Brasil.

A Análise de Conteúdo em Bardin (2011), adotada como metodologia nesta pesquisa, permitiu-nos fazer inferências a respeito do recorte do corpus definido, que tem como personagem o jogador Thiago Silva. Temos indicativos para afirmar que o caminho da aventura do herói, representado pelos rituais, separação-iniciação-retorno, aparece na história narrada. $\mathrm{O}$ atleta recebe o chamado para a prática esportiva e vai em busca do sucesso no futebol, o que implica separação da família em algum momento.

Em sua iniciação conta, muitas vezes, com o auxílio de uma figura protetora, enfrenta diversas provas e também convive com a derrota. No entanto, acaba por ser vitorioso no campo de batalha, faz sucesso no mundo profissional e retorna de sua jornada vitorioso. No retorno, traz a sabedoria que vai passar para a sua comunidade. Note-se, porém, que nem todas as características do herói estão presentes na história do jogador.

A constatação vem ao encontro de Campbell (2005) que afirma que algumas características são suprimidas nas narrativas, o que não impede que a jornada seja identificada como tal. Em nossa análise, percebemos que o jogador Thiago Silva não possui a característica desprezo em sua trajetória narrada pelo repórter Tino Marcos. No entanto, os principais atributos de mais fácil identificação com o herói estão presentes: vitória, amor, derrota, renascimento e persistência. 
À medida que procedemos à análise, comprovamos a predominância do primeiríssimo plano, seguido do primeiro plano na edição da reportagem da Série Seleção, o que nos indica a intenção de aproximar o telespectador da narrativa. O artifício acaba por trazer a audiência para dentro da história e inevitavelmente deixa latente a lógica das emoções, que se torna mais poderosa à medida que a matéria ultrapassa os sete minutos e o personagem ganha mais profundidade. Além da questão dos planos mais fechados, os recursos da dramaturgia do telejornalismo (COUTINHO, 2012) se fazem presentes na reportagem e são possíveis de identificar na edição.

A sonorização que ativa os sentidos durante a narrativa leva o telespectador a um sobe e desce intencional de emoções que conduzem a trama e o caráter espetacular da atuação do personagem. Nas situações que remetem à conquista, é possível evidenciar a utilização do sobe som. O recurso reforça a glória do atleta que ganha destaque na potência e na emoção da voz dos narradores da Rede Globo. A construção do personagem também se dá pelo uso das imagens em câmera lenta, que dão mais emoção e credibilidade ao mito do herói, principalmente, nos momentos em que o jogador comemora as vitórias em campo. A dramaticidade está expressa igualmente no uso de máscaras de pós-produção e fades na edição, no tom emocional dos textos e das sonoras selecionadas que, acompanhados dos recursos descritos acima, constroem uma narrativa épica.

Dessa maneira, podemos dizer que a Série Seleção trabalha com a construção do percurso heroico-mitológico do jogador da Seleção Brasileira, por meio da narrativa jornalística que conta sua vida. Ao percorrer os caminhos de análise da reportagem exibida durante a Copa do Mundo, palavras como aflição, ansiedade, tensão, pressão, emoção e choro estão muito presentes no texto construído pelo repórter.

O zagueiro Thiago Silva, destacado anteriormente como um bravo guerreiro que lutou para nascer, superou uma tuberculose e tem as qualidades necessárias para carregar a braçadeira de capitão, é mostrado como frágil e inseguro. A narrativa imagética, que aparece nos quadros de análise, permite-nos dizer que, em sua maioria, o primeiro plano é utilizado justamente para trazer, de uma forma mais evidente para o telespectador, os momentos de emotividade do jogador. As imagens ratificam a fragilidade do capitão brasileiro.

Os momentos de choro, de socos na cabeça, do jogador sentado sobre a bola e de costas para as cobranças de pênaltis contra o Chile ganham um robusto significado negativo, principalmente, quando repetidos nas reportagens. A partir disso, embasados em Ferrés (1998), podemos perceber a desconstrução dos personagens por meio do estereótipo negativo 
que foi ganhando força à medida que a Seleção Brasileira não apresentava grandes atuações individuas e coletivas nos jogos da Copa.

A partir desse recorte, que faz parte de uma pesquisa de mestrado, podemos concluir que o Jornal Nacional produz um discurso que constrói o herói antes da Copa do Mundo, a fim de vender o produto no qual está baseada uma grande cobertura midiática. A questão envolve índices de audiência muito significativos e somas astronômicas em direitos de transmissão e patrocínio. A Seleção Brasileira é apresentada como vencedora, mesmo antes da competição iniciar. A informação sobre as reais condições da equipe para enfrentar outras seleções é relegada a um segundo plano por meio das narrativas mitológicas e da dramaturgia do telejornalismo.

Porém, quando o desempenho não é o mesmo que foi prometido nas histórias das façanhas heroicas dos nossos atletas, a desconstrução dos personagens ganha força pelo uso do estereótipo negativo. De herói, o capitão Thiago Silva passou a ser vilão. Parece-nos uma estratégia para apagar os vestígios de um discurso falacioso que cai perante a realidade dos fatos que acontecem em campo. Por toda essa complexa rede de relações, o papel social do jornalismo fica comprometido e passamos a acompanhar o esvaziamento informativo em detrimento do espetáculo noticioso.

As fronteiras entre o que realmente é notícia e o entretenimento se mostram cada vez mais tênues. Colocar a credibilidade em risco pode enfraquecer ou até mesmo por fim a uma atividade social que é considerada uma das bases da democracia. Dessa maneira, acreditamos que é sempre oportuno repensar a importância das dinâmicas comunicacionais contemporâneas sob o prisma dos mitos, do esporte e do jornalismo, que estão presentes nas narrativas cotidianas de milhões de brasileiros.

\section{REFERÊNCIAS}

BARDIN, Laurence. Análise de conteúdo. Tradução de Luís Antero Reto e Augusto Pinheiro. São Paulo: Edições 70, 2011.

BARTHES, Roland. Mitologias. São Paulo: Difel, 1980.

BIRD, S. Elizabeth; DARDENNE, Robert W. Mito, registro e 'estórias': explorando as qualidades narrativas das notícias. In: TRAQUINA, Nelson (Org.). Jornalismo: questões, teorias e "estórias". Lisboa: Vega, 1999. p. 263-277.

CAMPBELL, Joseph. O herói de mil faces. São Paulo: Cultrix, 2005.

COUTINHO, Iluska. Dramaturgia do telejornalismo: a narrativa da informação em rede e nas emissoras de televisão de Juiz de Fora-MG. Rio de Janeiro: Muad, 2012. 
DaMATTA, Roberto. A bola corre mais que os homens. Rio de Janeiro: Rocco, 2006.

DURAND, Gilbert. As Estruturas Antropológicas do Imaginário: introdução à arquetipologia geral. São Paulo: Martins Fontes, 1997.

ELIADE, Mircea. Aspectos do Mito. Rio de Janeiro: Edições 70, 1989.

FERRÉS, Joan. Televisão subliminar: socializando através de comunicações despercebidas. Trad. Ernani Rosa e Beatriz A. Neves. Porto Alegre: Artmed, 1998.

HELAL, Ronaldo. As idealizações do sucesso no imaginário brasileiro: um estudo de caso. Logos: Comunicação e Universidade, Rio de Janeiro, v. 6, n. 1, p. 38-42, 1999.

HENDERSON, J. L. Os mitos antigos e o homem moderno. In: JUNG, C.G. O homem e seus símbolos. Rio de Janeiro: Nova Fronteira, 1977.

INSTITUTO BRASILEIRO DE GEOGRAFIA E ESTATÍSTICA. Pesquisa Nacional por Amostra de Domicílios 2013. Acesso à Internet e à Televisão e Posse do Telefone Móvel Celular Para Uso Pessoal. 2013. Disponível em: <http://biblioteca.ibge.gov.br/visualizacao/livros/liv93373.pdf>. Acesso em: 30 abr. 2015.

IBOPE MEDIA. Um país que respira esportes. Disponível $\mathrm{em}:<\mathrm{http}: / / \mathrm{www}$.ibopemedia.com/um-pais-que-respira-esportes/>. 2014. Acesso em: $10 \mathrm{jul}$. 2015.

O investimento publicitário em 2014. 2014. Disponível em:

<http://www.ibopemedia.com/investimentos-publicitario-de-2014/>. . Acesso em: 10 jul. 2015.

JORNAL NACIONAL. TV Globo. Não sei o que faria, confessa capitão Thiago Silva sobre conquista da Copa. 2014. Disponível em: <http://g1.globo.com/jornalnacional/noticia/2014/05/conheca-historia-por-tras-dos-craques-da-selecao-brasileira.html $>$. Acesso em: 11 ago. 2015.

Thiago Silva afirma que choro não interfere no desempenho em campo. 2014. Disponível em: <http://g1.globo.com/jornal-nacional/noticia/2014/07/thiago-silva-afirma-que-choro-nao-interfere-nodesempenho-em-campo.html>. Acesso em: 28 ago. 2015.

JUNG, Carl Gustav. O homem e seus símbolos. Rio de Janeiro: Nova Fronteira, 1977.

Arquetipos e inconsciente colectivo. Buenos Aires: Paidos, 1977.

LOVISOLO, Hugo. Esporte competitivo e espetáculo esportivo. In: MOREIRA, W W; SIMÕES, R. (Org.). Fenômeno esportivo no início de um novo milênio. Piracicaba: Editora Unimep, 2000. 
MEIO E MENSAGEM. Globo dedicou 90\% da grade à Copa. 2014. Disponível em:<http://www.meioemensagem.com.br/home/midia/noticias/2014/06/16/Globo-dedicou90-porcento-da-grade-a-Copa.html>. Acesso em: 30 jun. 2014.

MOTTA, Luiz Gonzaga. Explorações epistemológicas sobre uma antropologia da notícia. Revista FAMECOS. Porto Alegre, n. 19, p. 65-80, dez. 2002.

Análise Crítica da Narrativa. Brasília: Editora Universidade de Brasília, 2013.

SECRETARIA DE COMUNICAÇÃO SOCIAL DA PRESIDÊNCIA DA REPÚBLICA. Pesquisa Brasileira de Mídia 2015. Disponível em:

$<$ http://www.secom.gov.br/atuacao/pesquisa/lista-de-pesquisas-quantitativas-e-qualitativasde-contratos-atuais/pesquisa-brasileira-de-midia-pbm-2015.pdf>. Acesso em: 22 fev. 2015.

WOLTON, Dominique. Elogio do grande público: uma teoria critica da televisão. São Paulo: Ática, 2006.

Informar não é comunicar. Tradução Juremir Machado da Silva. Porto Alegre: Sulina, 2011. 